\title{
Understanding the formation process of the liquid slug in a hilly-terrain wet natural gas pipeline
}

\author{
Yang, Yan; Li, Jingbo; Wang, Shuli; Wen, Chuang
}

Published in:

Journal of Environmental Chemical Engineering

Link to article, DOI:

10.1016/j.jece.2017.08.010

Publication date:

2017

Document Version

Peer reviewed version

Link back to DTU Orbit

Citation (APA):

Yang, Y., Li, J., Wang, S., \& Wen, C. (2017). Understanding the formation process of the liquid slug in a hillyterrain wet natural gas pipeline. Journal of Environmental Chemical Engineering, 5(5), 4220-4228.

https://doi.org/10.1016/j.jece.2017.08.010

\section{General rights}

Copyright and moral rights for the publications made accessible in the public portal are retained by the authors and/or other copyright owners and it is a condition of accessing publications that users recognise and abide by the legal requirements associated with these rights.

- Users may download and print one copy of any publication from the public portal for the purpose of private study or research.

- You may not further distribute the material or use it for any profit-making activity or commercial gain

- You may freely distribute the URL identifying the publication in the public portal 


\section{Accepted Manuscript}

Title: Understanding the formation process of the liquid slug in a hilly-terrain wet natural gas pipeline

Authors: Yan Yang, Jingbo Li, Shuli Wang, Chuang Wen

PII: $\quad$ S2213-3437(17)30394-9

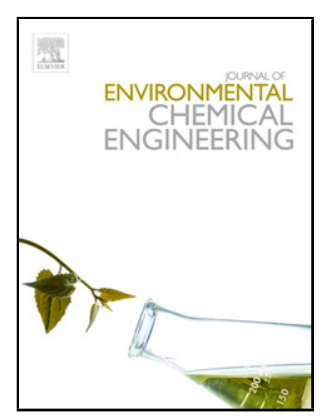

DOI: $\quad$ http://dx.doi.org/doi:10.1016/j.jece.2017.08.010

Reference: JECE 1805

To appear in:

Received date: $\quad$ 19-5-2017

Revised date: $\quad$ 7-8-2017

Accepted date: $\quad 8-8-2017$

Please cite this article as: Yan Yang, Jingbo Li, Shuli Wang, Chuang Wen, Understanding the formation process of the liquid slug in a hilly-terrain wet natural gas pipeline, Journal of Environmental Chemical Engineeringhttp://dx.doi.org/10.1016/j.jece.2017.08.010

This is a PDF file of an unedited manuscript that has been accepted for publication. As a service to our customers we are providing this early version of the manuscript. The manuscript will undergo copyediting, typesetting, and review of the resulting proof before it is published in its final form. Please note that during the production process errors may be discovered which could affect the content, and all legal disclaimers that apply to the journal pertain. 
Understanding the formation process of the liquid slug in a hilly-terrain wet

\section{natural gas pipeline}

Yan Yang ${ }^{1,2}$, Jingbo $\mathrm{Li}^{1}$, Shuli Wang ${ }^{1}$, Chuang Wen ${ }^{2, *}$

${ }^{1}$ School of Petroleum Engineering, Changzhou University, Zhonglou District,

Changzhou, Jiangsu 213016, China

${ }^{2}$ Department of Mechanical Engineering, Technical University of Denmark, Nils

Koppels Allé, 2800 Kgs. Lyngby, Denmark

*Corresponding author. Tel.: +45 4525 4168; fax: +45 4525 1961. E-mail address:

cwen@mek.dtu.dk (C. Wen). 


\begin{abstract}
In the present work, the liquid slug formation in a hilly-terrain pipeline is simulated using the Volume of Fluid model and RNG $k-\varepsilon$ turbulence model. The numerical model is validated by the experimental data of the horizontal slug flow. The influence of the pipe geometric structure and flow condition on the liquid slug formation is discussed including pipe diameter, inclination angle, gas superficial velocity and liquid holdup. The results show that the pipe is blocked by the liquid slug at the moment of slug formed. The pipe pressure suddenly increases, and then decreases gradually in the process of liquid slug formation and motion. The pipe pressure drop and liquid holdup decrease along with the increasing inclination angle of ascending pipe. On the contrary, they rise with the increase of the inclination angle of descending pipe. Higher gas superficial velocity and liquid holdup result in a larger pressure drop in the formation of a liquid slug, and correspondingly induces a slug flow more rapidly in the hilly-terrain pipelines.
\end{abstract}

Key words: liquid slug; pipe diameter; inclination angle; gas superficial velocity; liquid holdup

\title{
Nomenclature
}

$\begin{array}{lcl}C_{1 \varepsilon} & {[-]} & \text { constant } \\ C_{2 \varepsilon} & {[-]} & \text { constant } \\ D & {[\mathrm{~mm}]} & \text { pipe diameter } \\ \vec{F} & {[\mathrm{~N}]} & \text { external body force }\end{array}$




\begin{tabular}{|c|c|c|}
\hline$F_{\text {vol }}$ & {$[\mathrm{N}]$} & surface force \\
\hline$G_{b}$ & {$[-]$} & generation of turbulence kinetic energy due to buoyancy \\
\hline$G_{k}$ & {$[-]$} & $\begin{array}{l}\text { generation of turbulence kinetic energy due to mean } \\
\text { velocity gradients }\end{array}$ \\
\hline$g$ & {$\left[\mathrm{~m} / \mathrm{s}^{2}\right]$} & acceleration of gravity \\
\hline$h$ & {$[\mathrm{~mm}]$} & the level of stagnant liquid \\
\hline$k$ & {$\left[\mathrm{~m}^{2} \mathrm{~s}^{-2}\right]$} & turbulent kinetic energy \\
\hline$L$ & {$[\mathrm{~m}]$} & pipeline length \\
\hline$\dot{m}_{p q}$ & {$[-]$} & the mass transfer from phase $p$ to phase $q$ \\
\hline$\dot{m}_{q p}$ & {$[-]$} & the mass transfer from phase $q$ to phase $p$ \\
\hline$n$ & {$[-]$} & surface normal \\
\hline$\hat{n}$ & {$[-]$} & unit normal \\
\hline$p$ & {$[\mathrm{~Pa}]$} & pressure \\
\hline$Q$ & {$\left[\mathrm{~m}^{3} \mathrm{~s}^{-1}\right]$} & volume of pipe \\
\hline$Q_{L}$ & {$\left[\mathrm{~m}^{3} \mathrm{~s}^{-1}\right]$} & volume of stagnant liquid \\
\hline$R_{\varepsilon}$ & {$[-]$} & additional term. \\
\hline$S_{a q}$ & {$[-]$} & source term \\
\hline$S_{k}$ & {$[-]$} & source term \\
\hline$S_{\varepsilon}$ & {$[-]$} & source term \\
\hline$t$ & {$[\mathrm{~s}]$} & time \\
\hline$u$ & {$\left[\mathrm{~ms}^{-1}\right]$} & velocity \\
\hline$V_{G}$ & {$\left[\mathrm{~ms}^{-1}\right]$} & inlet gas velocity \\
\hline
\end{tabular}




$\begin{array}{ccc}V_{S L} & {\left[\mathrm{~ms}^{-1}\right]} & \text { superficial liquid velocity } \\ V_{S G} & {\left[\mathrm{~ms}^{-1}\right]} & \text { superficial gas velocity } \\ Y_{M} & {[-]} & \text { contribution of the fluctuating dilatation in compressible } \\ & & \text { turbulence to the overall dissipation rate }\end{array}$

Greek letters

\begin{tabular}{|c|c|c|}
\hline$\alpha$ & {$[-]$} & volume fraction \\
\hline$\alpha_{k}$ & {$[-]$} & constant \\
\hline$\alpha_{\varepsilon}$ & {$[-]$} & constant \\
\hline$\beta$ & {$[-]$} & constant \\
\hline$\varepsilon$ & {$[-]$} & turbulent dissipation rate \\
\hline$\delta_{i j}$ & {$[-]$} & Kronecker delta \\
\hline$\mu$ & {$\left[\mathrm{m}^{2} \mathrm{~s}^{-1}\right]$} & dynamic viscosity \\
\hline$\rho$ & {$\left[\mathrm{kgm}^{-3}\right]$} & density \\
\hline$\theta$ & {$\left[{ }^{\circ}\right]$} & inclination angle of pipe \\
\hline$\theta_{1}$ & {$\left[{ }^{\circ}\right]$} & inclination angle of descending pipe \\
\hline$\theta_{2}$ & {$\left[{ }^{\circ}\right]$} & inclination angle of ascending pipe \\
\hline$\kappa$ & {$[-]$} & defined in terms of the divergence of the unit normal \\
\hline
\end{tabular}




\section{Introduction}

The natural gas field usually locates in hilly or basin region, and then the hilly-terrain pipelines are used inevitably. The wet gas transportation approach is widely used in gathering transport system for gas field. The water in wet gas can assemble in the low-lying pipes, and becomes stagnant liquid in the process of transporting wet gas. It leads to the formation of the liquid slug or the slug flow, which can cause a shapely pressure and liquid holdup (liquid volume fraction) fluctuation in the pipeline system. The intermittent stress in the pipelines can affect the normal operation, accelerate the corrosion problem and even damage the transporting equipment [1-3]. Therefore, it is important to study and predict the slug flow in the hilly-terrain pipelines.

For the slug flow, the study mainly focuses on the horizontal pipe, vertical pipe and hilly-terrain pipes. For the horizontal pipelines, Kordyban and Ranov [4] introduced a classic Kelvin-Helmholtz instability theory to explain the mechanism of the slug formation. They found that the slug formed when the wave length formed in the gas - liquid surface was greater than the height of gas space. Woods and Hanratty [5] proposed an approach to predict the stability of liquid slug whether it is determined by the volume flow in and out of the slug. A prediction method based on one-dimensional two-fluid model was presented for predicting hydrodynamic slug initiation and growth by Issa and Kempf [6]. The approach was used for the numerical simulation in horizontal, inclined and V-section pipes, and the numerical results were compared with the experimental data. Al-Safran [7] developed a predictive empirical 
correlation for predicting slug frequency in gas-liquid two-phase horizontal pipes. For reducing predictive, a Poisson probability model was proposed to predict slug frequency in gas-liquid pipes [8]. Al-Safran et al. [9] then proposed a new empirical relationship to predict slug liquid holdup in high viscosity liquids. The new empirical relationship showed a better capability than the low viscosity empirical relationship because the viscosity term was included in the new model.

For the studies of a slug in the vertical pipelines, Clarke and Issa [10] presented a numerical model to predict a single Taylor bubble velocity in the vertical tubes using the ensemble average transport equations and $k-\varepsilon$ turbulence model. Taha and Cui [11] used the Volume of Fluid (VOF) model to simulate the motion of a single Taylor bubble in the vertical tubes and obtained the shape and flow parameters of the slug. Mayor et al. [12] carried out an experiment for slug flow in a vertical pipe by employing a non-intrusive image analysis technique and proposed a correlation for the bubble-to-bubble interaction. Abdulkadir et al. [13] conducted the experimental and numerical studies in the vertical pipes with $6 \mathrm{~m}$ long and $0.067 \mathrm{~m}$ internal diameter. The computational results were reasonably in good agreement with the experimental data.

Zheng et al [14] developed a slug-tracking model to track the behavior of a slug, including the slug generation, dissipation, shrink and grow in hilly-terrain pipelines. Henau and Raithby [15] investigated the slug behavior in two-phase pipes which contained several uphill and downhill sections. Al-Safran et al. [16] carried out several experiments in a $420 \mathrm{~m}$ long smooth steel pipe flow loop which included a 
hilly-terrain test section and found five possible flow behavior categories in hilly-terrain section. Ersoy et al. [17] investigated gas-oil-water three-phase slug flow in hilly-terrain pipelines and obtained the flow characteristics of a slug.

The studies on the gas-liquid slug flow are mainly focused on the horizontal and vertical pipelines. However, the formation and motion of a single liquid slug still need to be further studied in hilly-terrain pipelines, in particular the existence of the stagnant liquids. In this paper, the numerical study is carried out to understand the formation process of a single liquid slug in hilly-terrain pipelines. The influence of geometric structure and flow conditions on liquid slug formation is analyzed in detail, including the pipe diameter, inclination angle, gas superficial velocity and liquid holdup.

\section{Mathematical model}

The slug flow is a sort of complex gas-liquid two-phase flow, which has a distinct phase interface. The interface catching is a key step for the simulation of the liquid slug. The VOF model is a kind of surface-tracking technology based on the fixed Eulerian mesh and it can be used for modeling two or more immiscible fluids. Therefore, the VOF model is employed here to track the gas-liquid phase interface in hilly-terrain pipelines. In addition, the turbulence model is necessary due to the fact that the flow is turbulent in our simulation.

\subsection{Governing equations}

Continuity equation [18]: 


$$
\frac{\partial \rho}{\partial t}+\frac{\partial}{\partial x_{i}}\left(\rho u_{i}\right)=0
$$

\section{Momentum equation [19]:}

The momentum equation is solved throughout the computational domain, and the resulting velocity field is shared among all the phases.

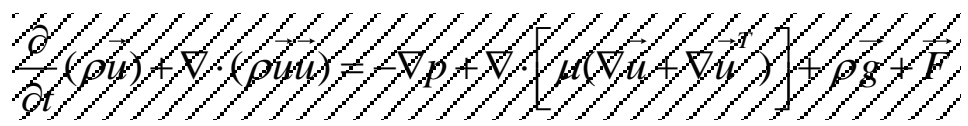

where $\rho$ is the density, $u$ is the velocity, $p$ is the static pressure, $\mu$ is the dynamic viscosity, $\rho \vec{g}$ is the gravitational body force and $\vec{F}$ is an external body force, $t$ is the time.

\subsection{Volume fraction equation}

The volume fraction of each phase in each grid cell is calculated throughout the domain. The interface between two phases is tracked by solving the continuity equation for the volume fraction of one (or more) of the phases. The volume fraction equation is as follows [20]:

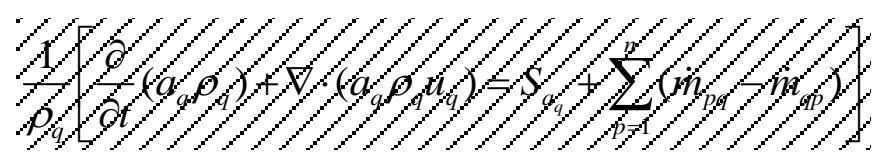

where $\dot{m}_{p q}$ is the mass transfer from phase $q$ to phase $p$ and $\dot{m}_{q p}$ is the mass transfer from phase $p$ to phase $q, \alpha_{q}$ is the volume fraction of phase $q, S_{\alpha_{q}}$ is the source term.

\subsection{Continuum surface force model}

The effect of surface force along the interface is included in the VOF model. The continuum surface force (CSF) model proposed by Brackbill et al. [21] is used in this paper. It is implemented as a source term in the momentum equation. The surface 
force $F_{v o l}$ is expressed as follows:

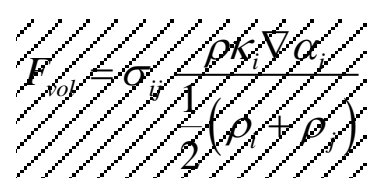

where $\sigma_{i j}$ is the surface tension coefficient between phase $i$ and $j, \alpha_{i}$ is the volume fraction of phase $i, \rho_{i}$ and $\rho_{j}$ is the density of phase $i$ and $j . \rho$ is the volume-averaged density computed by Eq. (5):

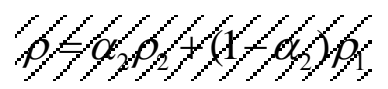

The curvature, $\kappa$, is defined in terms of the divergence of the unit normal, $\hat{n}$ :

$$
\mathscr{H} / \mathscr{P} / \hat{X}
$$

where

$$
\begin{gathered}
\hat{n}=\frac{n}{|n|} \\
n=\$ Q_{2}
\end{gathered}
$$

where $n$ is the surface normal, defined as the gradient of the $\alpha_{q}$.

\subsection{Turbulence model}

Depending on the information required, different turbulence models can be applied, from $k-\varepsilon$ model, shear stress transport model, large eddy simulation to direct numerical simulation [22-24]. Among these models, the RNG $k-\varepsilon$ turbulence model employs an additional term in its dissipation rate equation that can improve the accuracy for rapidly strained flow. It is more suitable for simulating large curvature and strain rate flow. The RNG $k-\varepsilon$ turbulence model is employed here because the flow turns at the elbow of the pipe which connects the uphill section and downhill section in hilly-terrain pipelines. The turbulence kinetic energy, $k$, and its rate of 
dissipation, $\varepsilon$, are as follows [25]:

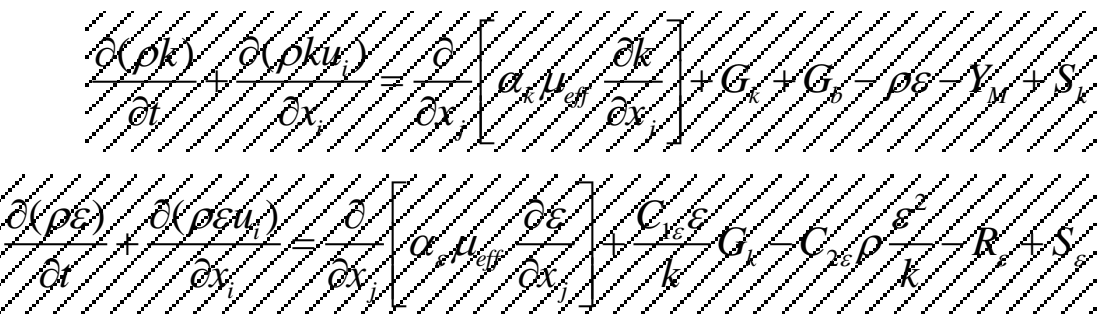

where $\mu_{e f f}$ is the effective eddy viscosity. $G_{k}$ is the generation of turbulence kinetic energy due to the mean velocity gradients; $G_{b}$ represents the generation of turbulence kinetic energy due to buoyancy; $Y_{M}$ represents the contribution of the fluctuating dilatation in compressible turbulence to the overall dissipation rate. $R_{\varepsilon}$ is the additional term. The quantities $\alpha_{k}$ and $\alpha_{\varepsilon}$ are the inverse effective Prandtl numbers for $k$ and $\varepsilon$, respectively. $S_{k}$ and $S_{\varepsilon}$ are the source terms. The $C_{1 \varepsilon}$ and $C_{2 \varepsilon}$ are constants.

\section{Numerical schemes}

\subsection{Geometric model}

The sketch of the hilly - terrain pipeline is shown in Figure 1. This pipeline contains a descending pipe and an ascending pipe, respectively. The inclination angles of two pipes are $\theta_{1}$ and $\theta_{2}$. The stagnant liquid is water and the gas phase is methane. Two pressure monitoring points $(P 1$ and $P 2)$ are set at the center of the pipe cross section which locates in $x=-15 D$ and $x=15 D$. The pipe pressure drop is the value of $|P 1-P 2|$ in this paper.

The hilly-terrain pipe model includes a downhill section and an uphill section, as shown in Figure 2. The pipe diameter is defined as $D$ and the length of every section is $50 \mathrm{D}$ to ensure a fully developed flow 


\subsection{Mesh generation}

The computational domain should be meshed after the geometric model is established. The commercial software ANSYS ICEM CFD is selected as the meshing tool. The hexahedral mesh and O-block technology is selected as the grid partition strategy for improving the quality of the grid. The grid system is shown in Figure 3. The computational grid of 317,760 hexahedral cells is employed for the simulation after the grid independent tests.

\subsection{Numerical method}

The simulation is achieved in commercial software ANSYS Fluent. The VOF multiphase model and the RNG $k-\varepsilon$ turbulence model are applied for tracking the gas-liquid phase interface. The boundary conditions of pipe inlet and outlet are defined as the velocity-inlet and the outflow, respectively. The wall condition is set to be frictionless with no slipping [26]. The operating pressure is $0 \mathrm{~Pa}$ and the reference pressure location is set at the center point of pipe outlet. The Pressure-Velocity coupling scheme is performed with the PISO approach. The QUICK scheme is implemented for discretizing continuity equation, momentum equation and turbulence equation. The Geometric Reconstruction scheme (Geo-Reconstruct) is chosen for the volume fraction equation. The time step size is $0.0001 \mathrm{~s}$ for proving calculation convergence in every time step.

\section{Results and discussion}

\subsection{Model validation and verification}

In this paper the experimental data obtained by Heywood and Richardson [27] 
are employed to validate our numerical method. The experiments were carried out in an air-water flow loop system, which included a horizontal pipeline of $42 \mathrm{~mm}$ inner diameter. The $\gamma$-ray absorption method was used to measure the slug liquid holdup. Six experimental data in the same superficial liquid velocity $(0.978 \mathrm{~m} / \mathrm{s})$ were selected for the model validation in different superficial gas velocities. The results of the comparison between the experimental and numerical data are shown in Figure 4. It shows that the maximum relative error is $5.9 \%$ in superficial gas velocity of $4.145 \mathrm{~m} / \mathrm{s}$. Therefore, the numerical results are in good agreement with the experimental data.

The mesh quality is an important factor in numerical simulation. The appropriate mesh size can ensure the accuracy of calculation by taking into account the computational efficiency. The grid independence is tested in three cells number of about $180,000,380,000$ and 780,000, respectively. The pressure drop calculated with different cells is shown in Figure 5. It shows that the computed results with 180,000 grid cells are much different from other two cases. The difference of the pressure drop between 380,000 and 780,000 cells is tiny. Therefore, the numerical simulation is performed with 380,000 cells considering the computational accuracy and efficiency.

\subsection{Liquid slug formation process}

Figure 6 shows the formation process of a liquid slug in the $150 \mathrm{~mm}$ diameter pipe with the inclination angle of $\theta_{2}=\theta_{2}=5^{\circ}$. The inlet gas velocity is $6.5 \mathrm{~m} / \mathrm{s}$, and the ratio of the stagnant liquid height, $h$, to the pipe diameter is $0.75(h / D=0.75)$. The phase fraction distribution with different moment $(t)$ is described in the contours. The blue region represents the gas phase, while the red one represents the liquid phase. 
The axis, $x$ is the position coordinates of pipe along the flow direction.

The flow area decreases due to the stagnant liquid accumulated at the bottom of hilly-terrain pipes, which cause the increase of the gas velocity. This flow structure further induces the decline of the pressure above the liquid level. Then suction force is generated in the vertical upward, which destroys the stability of the gas-liquid interface. For this reason, a wave crest forms. When the liquid level uplifts to the top of the pipe and blocks the entire pipe cross section, the liquid slug flow finally appears $(t=0.005 \mathrm{~s}-0.100 \mathrm{~s}$ in Figure 6$)$. The liquid slug then goes into the next process of moving forward under the pressure difference between the upstream and downstream of the slug flow $(t=0.105-0.120 \mathrm{~s}$ in Figure 6$)$.

\subsection{Effect of pipe diameter}

In this section, the influence of the pipe diameter on the formation of a liquid slug is discussed in detail. The pipe diameters are $90 \mathrm{~mm}, 120 \mathrm{~mm}, 150 \mathrm{~mm}, 180 \mathrm{~mm}$ and $210 \mathrm{~mm}$, respectively. The length of the ascending and descending pipes is $50 \mathrm{D}$, while the inclination angle is set to be $5^{\circ}$. The numerical simulation is implemented in the identical condition which the inlet gas velocity is $6.5 \mathrm{~m} / \mathrm{s}$ with $h / D=0.75$.

Figure 7 shows the pressure curves of point P1 and P2 with the flow time in different pipe diameters. It shows that the pressure nearly maintains a constant value at point P2, while fluctuates sharply at point P1. Moreover, the pressure increases suddenly and then declines slowly at point P2. The reason is that the flow area of the gas phase decreases gradually because of the pressure fluctuation during the formation process of the liquid slug. The liquid slug then moves under the pressure 
difference between its upstream and downstream flow.

The pressure drops in different pipe diameter at the moment of slug formed are shown in Figure 8. The pressure drop increases along with the pipe diameter. The pressure drop ranges from 40,000 $\mathrm{Pa}$ to $82,000 \mathrm{~Pa}$. The rate of increasing pressure drop is about $30 \%$ with the pipe diameter from $90 \mathrm{~mm}$ to $210 \mathrm{~mm}$. Figure 9 describes the slug liquid holdup in different pipe diameters. We can see that the liquid holdup increases slowly in the pipe diameters from $90 \mathrm{~mm}$ to $180 \mathrm{~mm}$, while it declines slightly in the $210 \mathrm{~mm}$ diameter pipe. However, the value of slug liquid holdup distributes by approximately 0.5 in the entire pipe diameters.

\subsection{Effect of pipe inclination angle}

The pipe inclination angle plays an important role in the slug formation in hilly terrain pipelines. The effects of the inclination angle of ascending and descending pipes are analyzed in this section. The pipe diameter is $150 \mathrm{~mm}$ and the inclination angle are $3^{\circ}, 5^{\circ}, 8^{\circ}, 10^{\circ}$ and $12^{\circ}$, respectively. The inlet gas velocity is $6.5 \mathrm{~m} / \mathrm{s}$ and the ratio of the stagnant liquid volume $\left(Q_{L}\right)$ at the bottom of the pipe to the volume of pipe $(Q)$ is a fixed value.

The pressure drop and liquid holdup in different ascending angles with the descending angle of $3^{\circ}$ are shown in Figure 10 and Figure 11, respectively. It can be seen that the pressure drop declines with the increasing ascending angle. The pressure drop reduces the maximum about $37.5 \%$, when the ascending angle changes from $3^{\circ}$ to $5^{\circ}$. The change trend of the liquid holdup is similar to the pressure drop that it decreases with the increasing ascending angle. The liquid holdup at the high 
ascending angle of $12^{\circ}$ is only 0.35 , reducing $40 \%$ compared to the one at the lower ascending angle of $3^{\circ}$.

The pressure drop and liquid holdup in different descending angles are shown in Figure 12 and Figure 13, respectively, when the ascending angle is fixed at $5^{\circ}$. The pressure drop and liquid holdup have the similar relationship that they both increase with the increasing descending angle. The pressure drop ranges from $17,000 \mathrm{~Pa}$ to 138,000 $\mathrm{Pa}$, while the liquid holdup changes from 0.35 to 0.57 . The maximum presusre drop appears in the descending angle from $10^{\circ}$ up to $12^{\circ}$. However, the maximum liquid holdup presents in the descending angle from $5^{\circ}$ to $8^{\circ}$.

\subsection{Effect of gas superficial velocity and liquid holdup}

Figure 14 shows the effect of the gas superficial velocity on the pressure drop during the formation of liquid slug flow under different liquid holdups. We can see that the increasing gas superficial velocity induces a larger pressure drop in the same liquid holdup, $h / D$. The reason is that the greater gas superficial velocity can carry more liquids, which results in more loss of the kinetic energy during the formation of liquid slug. It correspondingly determines the higher rise of the gas pressure in the upstream of the slug. Moreover, in the higher liquid holdup, the increase of the gas superficial velocity induces a sharper increase of pressure drop. In the conditions of $h$ / $\mathrm{D}=0.6, \mathrm{USG}=2.5 \sim 4.5 \mathrm{~m} / \mathrm{s}$ and $\mathrm{h} / \mathrm{D}=0.65, \mathrm{USG}=2.5 \sim 3.5 \mathrm{~m} / \mathrm{s}$, the pipeline pressure drop is $0 \mathrm{~Pa}$ because there is no slug flow in the hilly pipelines.

The change of the gas superficial velocity at the pipe inlet also affects the phase distribution of the gas-liquid two-phase flows. Figure 15 shows the gas-liquid 
two-phase distribution in the same liquid holdup under the conditions of $U_{S G}=3.5 \mathrm{~m} / \mathrm{s}$ and $U_{S G}=5.5 \mathrm{~m} / \mathrm{s}$. From the time point of view, the formation of the liquid slug is faster with a larger gas superficial velocity. From the figures at $U_{S G}=3.5 \mathrm{~m} / \mathrm{s}, t=0.20 \mathrm{~s}$, and $U_{S G}=5.5 \mathrm{~m} / \mathrm{s}, t=0.12$, it can be seen that more liquids are lifted to the top to block the pipeline as a result of larger gas superficial velocity during the formation of liquid slug, leading to higher fluctuations of the liquid level. During the growth process of liquid slug flow, such as in the figures of $U_{S G}=3.5 \mathrm{~m} / \mathrm{s}, t=0.20 \mathrm{~s} \sim 0.52 \mathrm{~s}$ and $U_{S G}=5.5$ $\mathrm{m} / \mathrm{s}, t=0.12 \mathrm{~s} \sim 0.40 \mathrm{~s}$, the throwing phenomenon of the slug flow becomes more obvious that more liquids are reeled into the liquid slug by the slug head, which makes that both of the length of the slug head and slug body are greater than those in a smaller gas superficial velocity. This is because the liquid slug body can obtain higher kinetic energy driven by the upstream natural gas with a larger gas superficial velocity, which strengthens the ability of the slug to entrain the liquids ahead.

Figure 16 describes the gas-liquid two-phase distribution at different liquid level of $h / D=0.65$ and $h / D=0.85$. For example, the liquid slug forms in a shorter time under the condition of $h / D=0.85$. Compared to the phase distributions of $h / D=0.65$ and $h / D=0.85$, we can conclude that higher liquid level is easier to induce the formation of the liquid slug. Moreover, more liquids are carried by the gas phase during the formation of the liquid slug in higher liquid level, resulting in more serious blocking in the pipeline. The throwing phenomenon of the slug head at $h / D=0.85$ is much more serious than that of $h / D=0.65$, which also leads to longer slug head and slug body in higher liquid level. When the liquids are thrown out of the slug head, the slug body 
gradually reduces until the slug disappears.

\section{Conclusions}

The VOF and RNG $k-\varepsilon$ turbulence models show the reasonable results in simulating the formation process of a liquid slug. The validation of the numerical model and mesh independence test are examined in this paper. The distinct gas-liquid two-phase distribution and the formation process of a liquid slug are obtained by numerical simulation in different pipe geometric parameters. The pipe cross-section is blocked by the liquid phase at the moment of a liquid slug formed. The pressure suddenly increases, and then declines gradually in process of liquid slug formation and motion. The pipe diameter has a tiny effect on the slug formation, since the pressure drop and the liquid holdup change little. When the inclination angle of the pipe varies, the similar trend occurs both for pipe pressure and liquid holdup. The pressure drop and liquid holdup decline with the increase of the ascending angle. On the contrary, they rise along with the increasing descend. It indicates that the inclination angle of a pipe is a key influence factor for the liquid slug formation. The increase of the gas superficial velocity and liquid holdup both causes the rise of the pressure drop, and correspondingly induces the formation of liquid slug in a shorter time.

\section{Acknowledgements}

This work was supported by the National Natural Science Foundation of China (51444005, 51606015, 51574045), the Natural Science Foundation of Jiangsu 
Province, China (BK20150270), and the General Program of Natural Science Research Project of Jiangsu Province Universities and Colleges (15KJB440001). The research leading to these results has received funding from the People Programme (Marie Curie Actions) of the European Union's Seventh Framework Programme (FP7/2007-2013) under REA grant agreement no. 609405 (COFUNDPostdocDTU).

\section{References}

[1] Yang Y, Li Z, Wen C. Effects of alternating current on X70 steel morphology and electrochemical behavior. Acta Metallurgica Sinica, 2013, 49(1): 43-50.

[2] Wen C, Li J, Wang S, Yang Y. Experimental study on stray current corrosion of coated pipeline steel. Journal of Natural Gas Science and Engineering, 2015, 27: $1555-1561$.

[3] Yang Y, Wang S, Wen C. Experimental study on alternating current corrosion of pipeline steel in alkaline environment. International Journal of Electrochemical Science, 2016, 11: 7150-7162.

[4] Kordyban E S, Ranov T. Mechanism of slug formation in horizontal two-phase flow. Journal of Fluids Engineering, 1970, 92(4):857-864.

[5] Woods B D, Hanratty T J. Relation of slug stability to shedding rate. International Journal of Multiphase Flow, 1996, 22(22):809-828.

[6] Issa R I, Kempf M H W. Simulation of slug flow in horizontal and nearly horizontal pipes with the two-fluid model. International Journal of Multiphase Flow, 2003, 29(1):69-95. 
[7] Al-Safran E. Investigation and prediction of slug frequency in gas/liquid horizontal pipe flow. Journal of Petroleum Science \& Engineering, 2009, 69(1):143-155.

[8] Al-Safran E M. Probabilistic modeling of slug frequency in gas/liquid pipe flow using poisson probability theory. Journal of Petroleum Science \& Engineering, 2015.

[9] Al-Safran E, Kora C, Sarica C. Prediction of slug liquid holdup in High viscosity liquid and Gas two-phase flow in Horizontal Pipes. Journal of Petroleum Science \& Engineering, 2015, 133:566-575.

[10]Clarke A, Issa R I. A numerical model of slug flow in vertical tubes. Computers \& Fluids, 1997, 26(4):395-415.

[11]Taha T, Cui Z F. CFD modelling of slug flow in vertical tubes. Chemical Engineering Science, 2006, 61(2):676-687.

[12]Mayor T S, Ferreira V, Pinto A M F R, et al. Hydrodynamics of gas-liquid slug flow along vertical pipes in turbulent regime-An experimental study. International Journal of Heat \& Fluid Flow, 2008, 29(4):1039-1053.

[13]Abdulkadir M, Hernandez-Perez V, Lo S, et al. Comparison of experimental and Computational Fluid Dynamics (CFD) studies of slug flow in a vertical riser. Experimental Thermal \& Fluid Science, 2015, 68:468-483.

[14]Zheng G, Brill J P, Taitel Y. Slug flow behavior in a hilly terrain pipeline. International Journal of Multiphase Flow, 1994, 20(1):63-79. 
[15]Henau V D, Raithby G D. A study of terrain-induced slugging in two-phase flow pipelines. International Journal of Multiphase Flow, 1995, 21(97):365-379.

[16]Al-Safran E, Sarica C, Zhang H Q, et al. Investigation of slug flow characteristics in the valley of a hilly-terrain pipeline. International Journal of Multiphase Flow, 2005, 31(3):337-357.

[17]Ersoy G, Sarica C, Al-Safran E, et al. Experimental investigation of three-phase gas-oil-water slug flow evolution in hilly-terrain pipelines. SPE Annual Technical Conference and Exhibition. Society of Petroleum Engineers, 2011.

[18]Wen C, Cao X, Yang Y, Li W. An unconventional supersonic liquefied technology for natural gas. Energy Education Science and Technology Part A: Energy Science and Research. 2012, 30(1): 651-660.

[19]Wen C, Cao X, Yang Y, Feng Y. Prediction of mass flow rate in supersonic natural gas processing, Oil \& Gas Science and Technology, 2015, 70(6): 1101-1109.

[20]Hirt C W, Nichols B D. Volume of fluid (VOF) method for the dynamics of free boundaries. Journal of Computational Physics, 1981, 39(1): 201-225.

[21]Brackbill J U, Kothe D B, Zemach C. A continuum method for modeling surface tension[J]. Journal of computational physics, 1992, 100(2): 335-354.

[22] Yang Y, Walther J H, Yan Y, Wen C. CFD modelling of condensation process of water vapor in supersonic flows. Applied Thermal Engineering, 2017, 115: 1357-1362. 
[23] Yang Y, Li A, Wen C. Optimization of static vanes in a supersonic separator for gas purification. Fuel Processing Technology, 2017, 156: 265-270.

[24] Yang Y, Wen C. CFD modeling of particle behavior in supersonic flows with strong swirls for gas separation. Separation and Purification Technology, 2017, 174: 22-28.

[25] Yakhot V, Orszag S A. Renormalization-group analysis of turbulence. Physical Review Letters, 1986, 57(14): 1722.

[26]Haghighi M, Hawboldt K A, Abdi M A. Supersonic gas separators: review of latest developments. Journal of Natural Gas Science and Engineering, 2015, 27: $109-121$.

[27]Heywood N I, Richardson J F. Slug flow of air-water mixtures in a horizontal pipe: determination of liquid holdup by $\gamma$-ray absorption. Chemical Engineering Science, 1979, 34(1):17-30. 


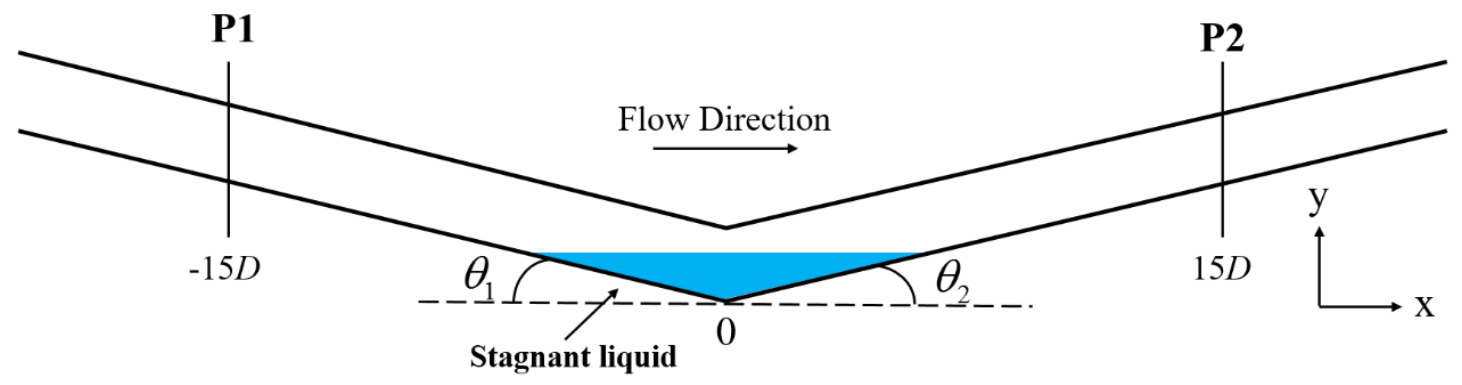

Figure 1 Sketch of the hilly-terrain pipeline

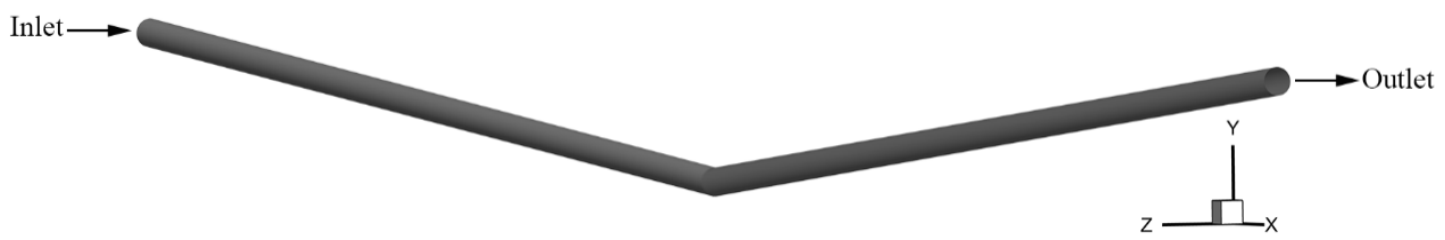

Figure 2 Computational domain
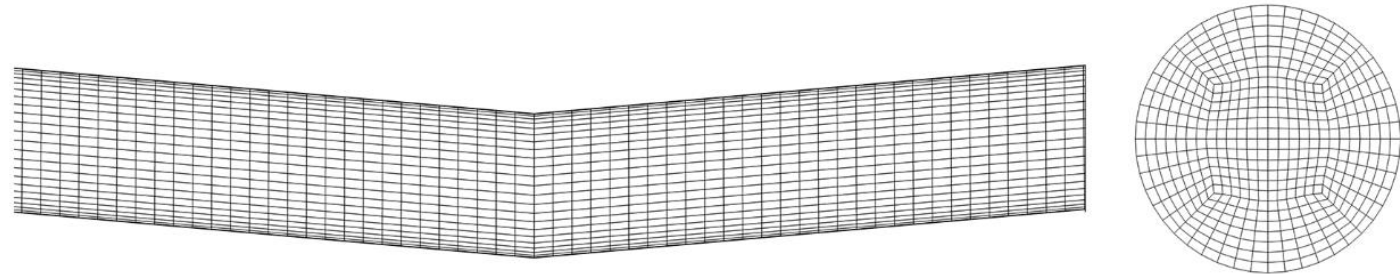

Figure 3 Mesh characteristic 


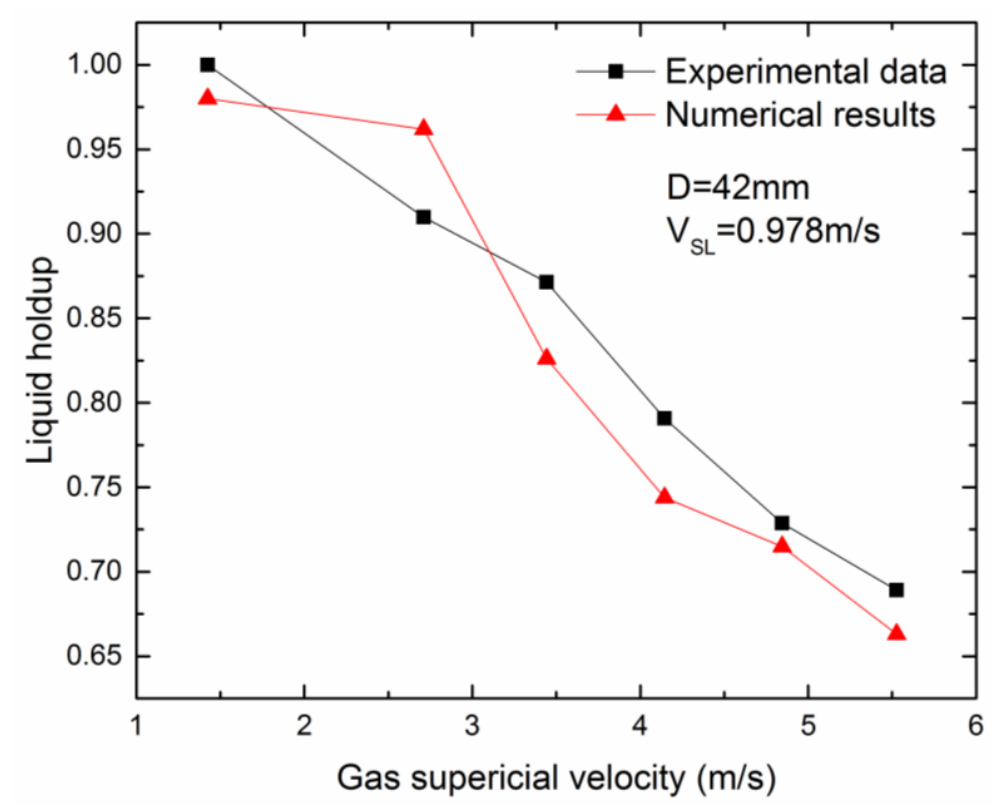

Figure 4 Comparison between experimental and numerical results in a horizontal pipe

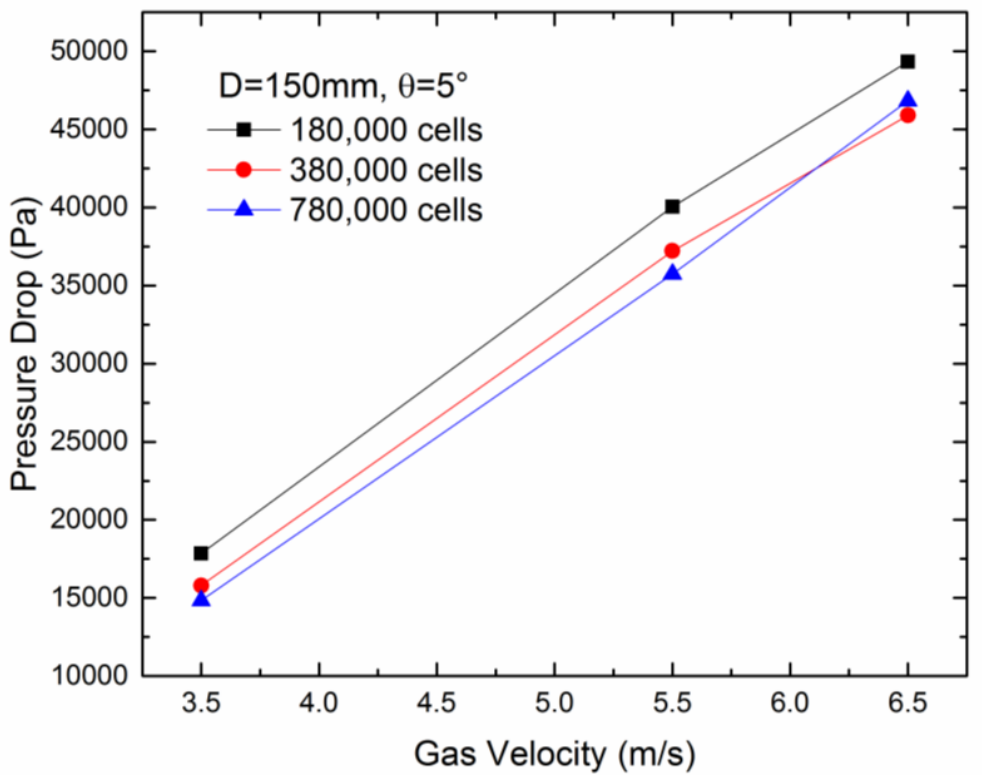

Figure 5 Pressure drop in different cell numbers 


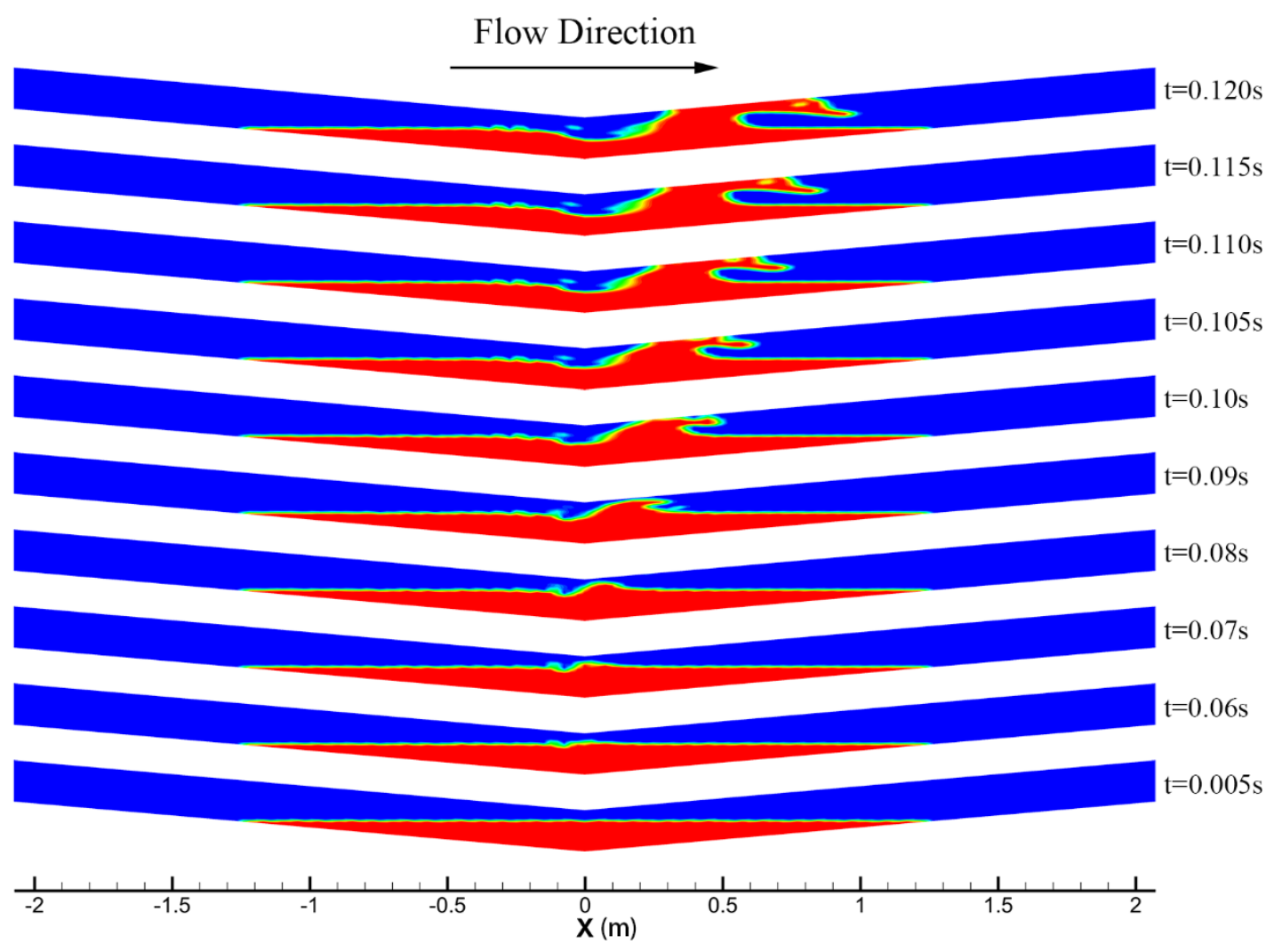

Figure 6 Formation process of a liquid slug 

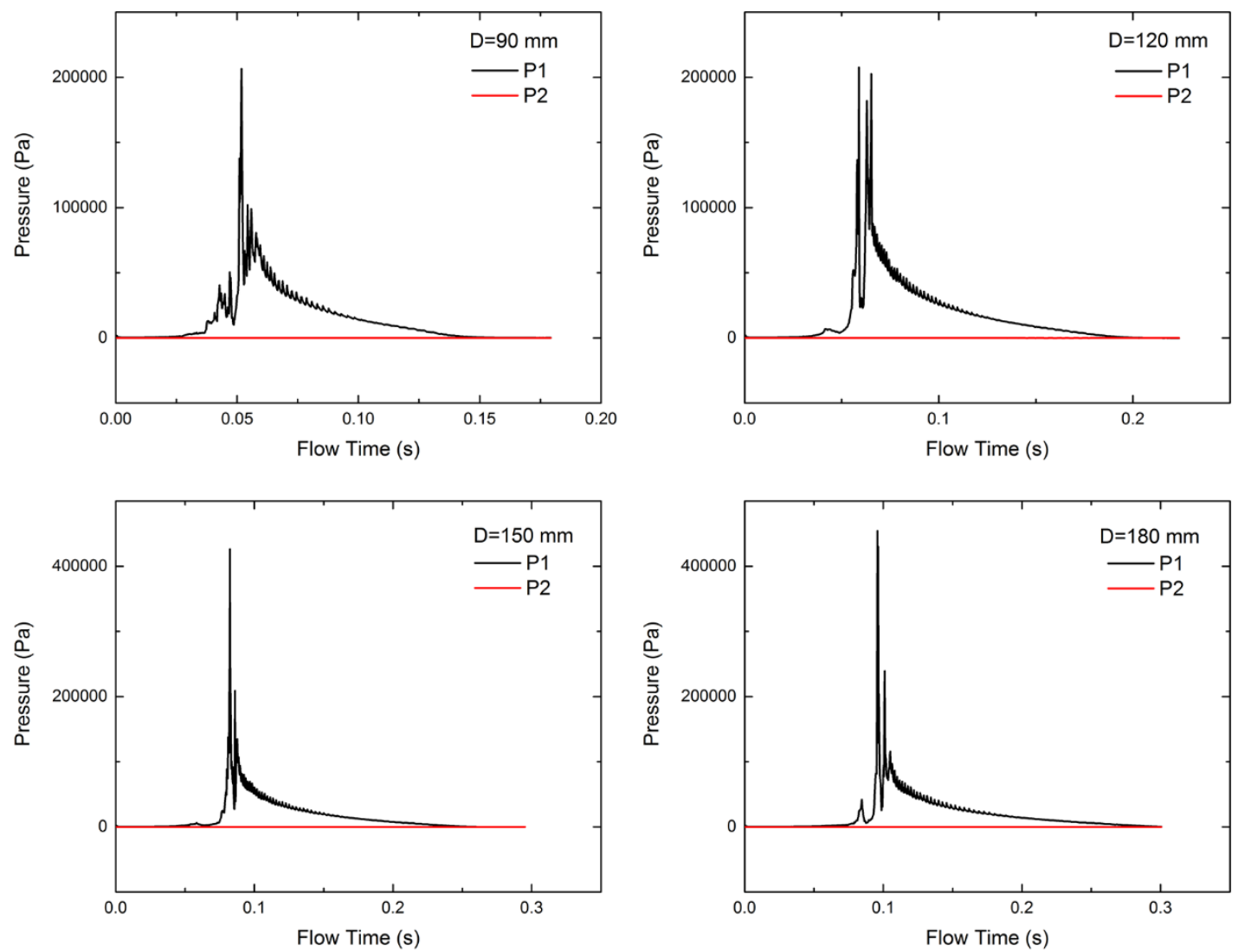

Figure 7 Pressure at point P1 and P2 in different pipe diameters

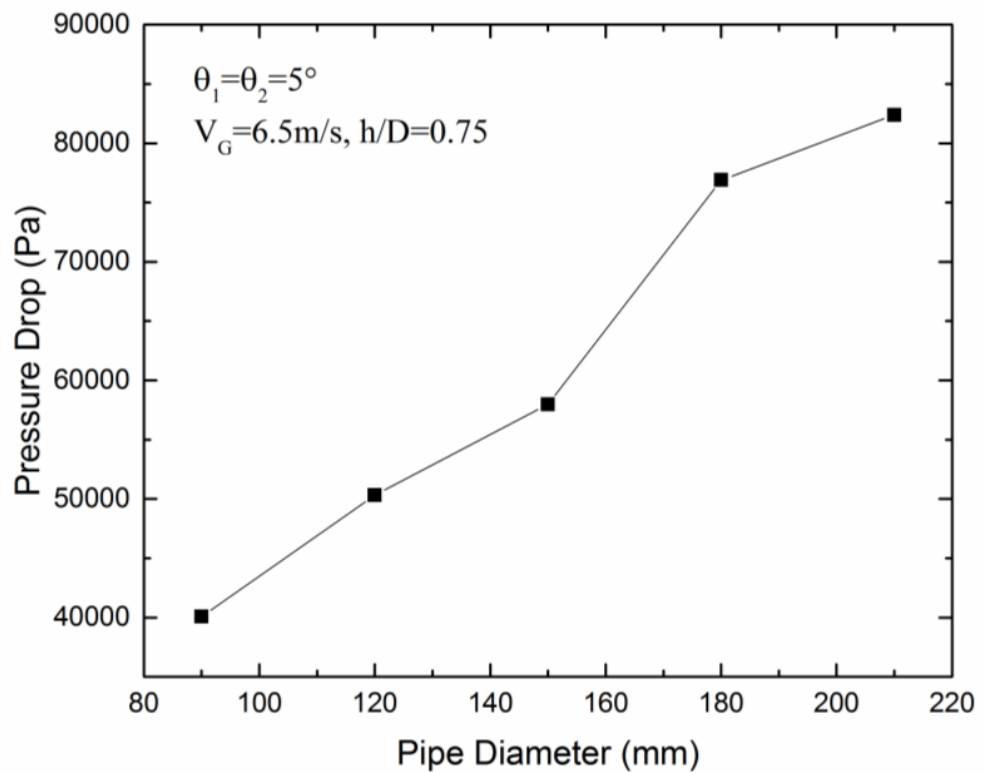

Figure 8 Influence of pipe diameter on pressure drop at the moment of slug formed 


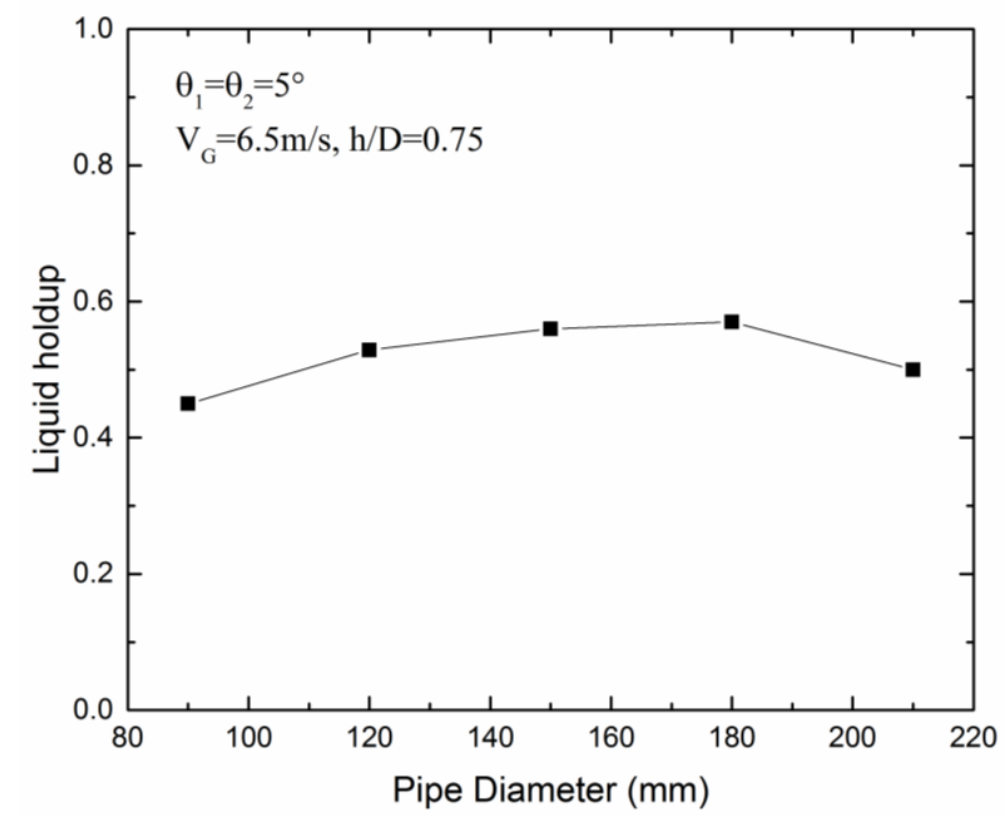

Figure 9 Influence of pipe diameter on liquid holdup at the moment of slug formed

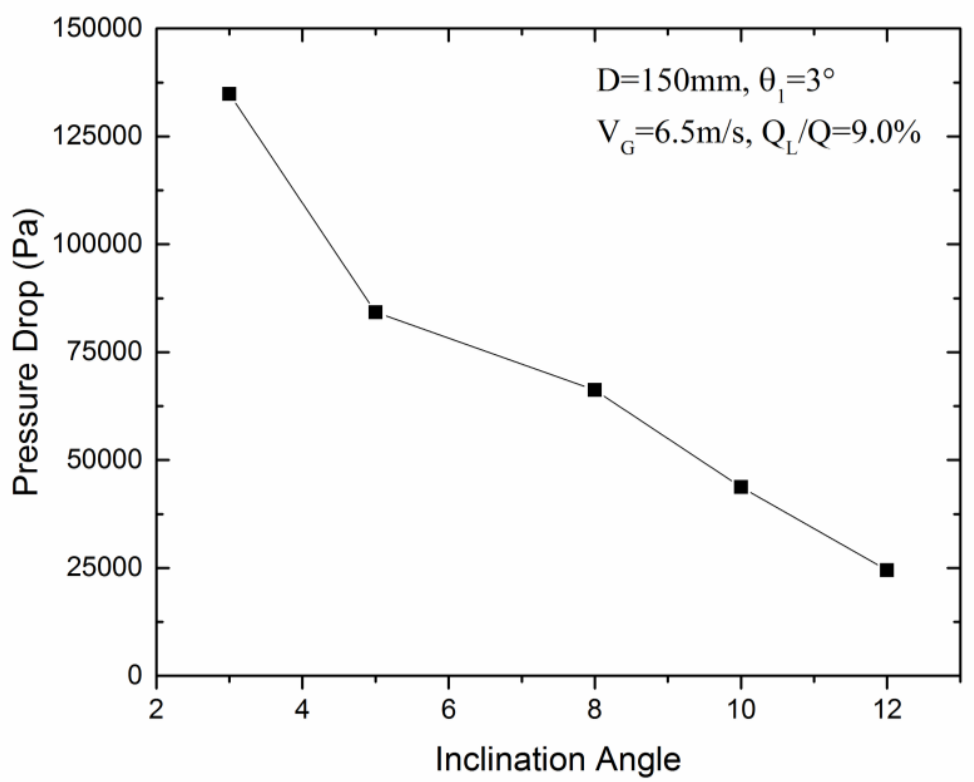

Figure 10 Pressure drop in different ascending angle at the moment of slug formed 


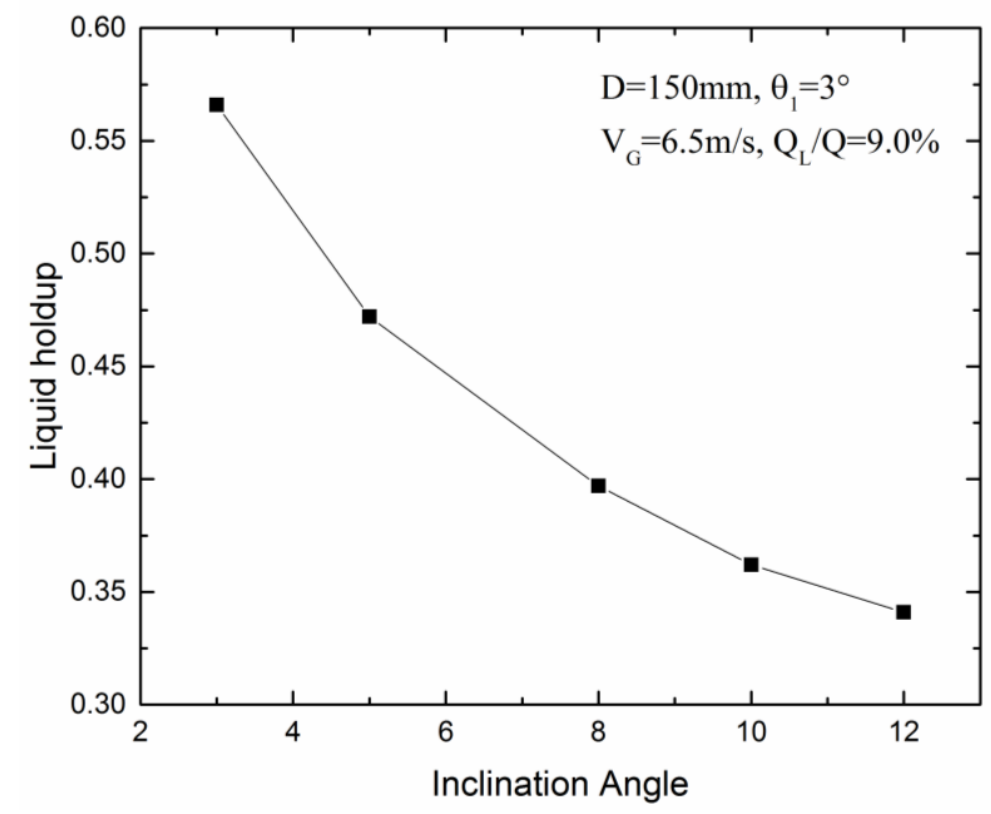

Figure 11 Liquid holdup in different ascending angle at the moment of slug formed

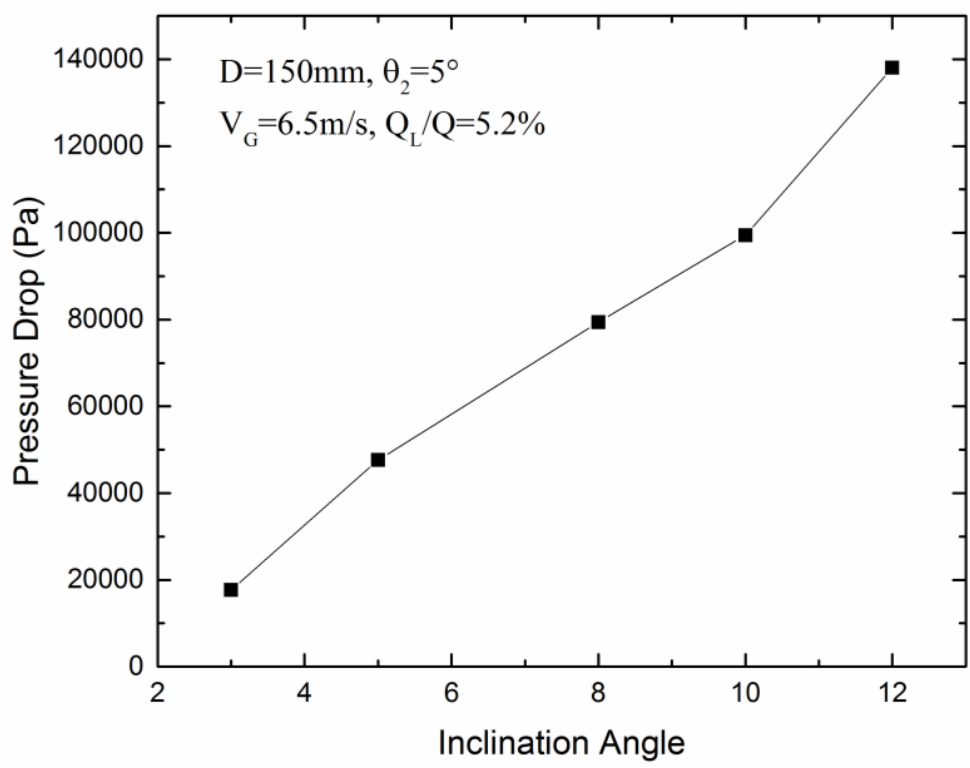

Figure 12 Pressure drop in different descending angle at the moment of slug formed 


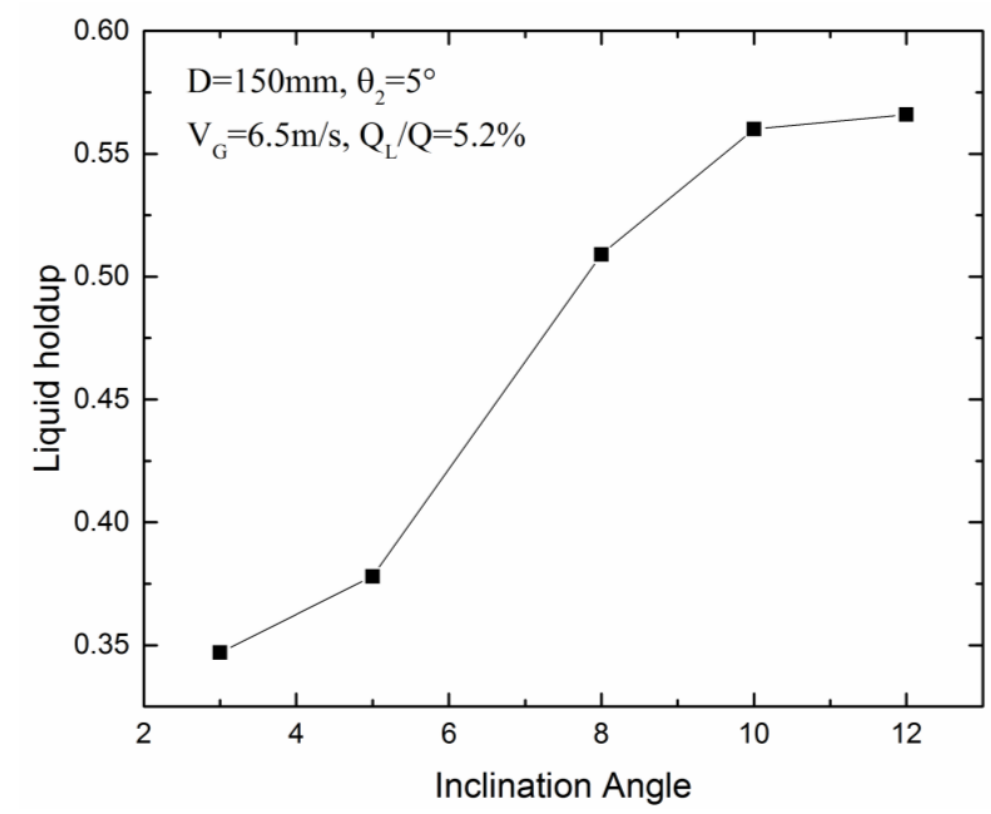

Figure 13 Liquid holdup in different descending angle at the moment of slug formed

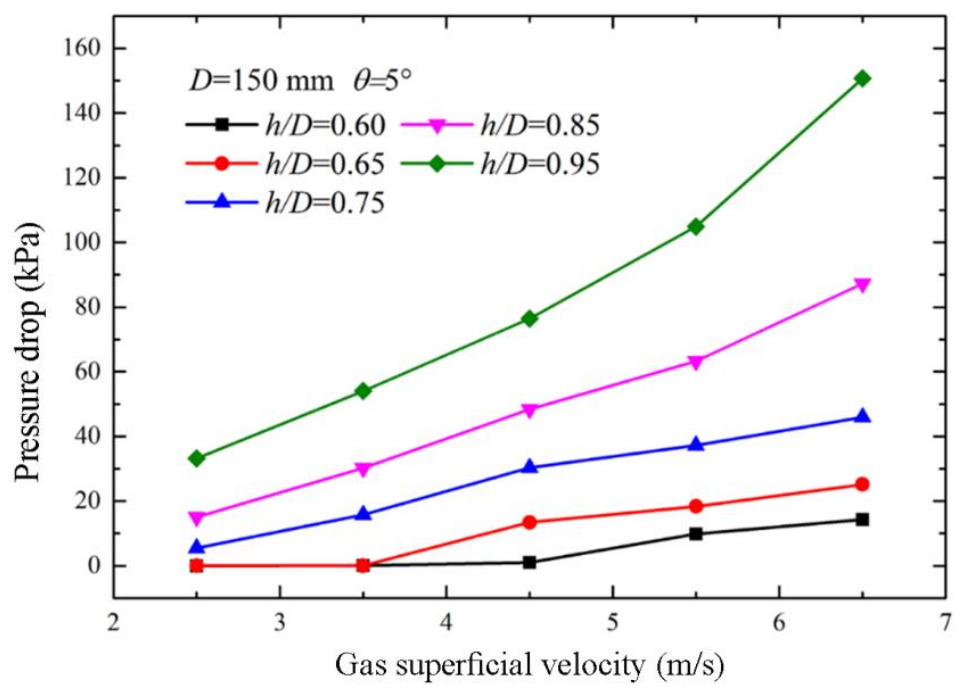

Figure 14 Pressure drop in different gas superficial velocity and liquid holdup 


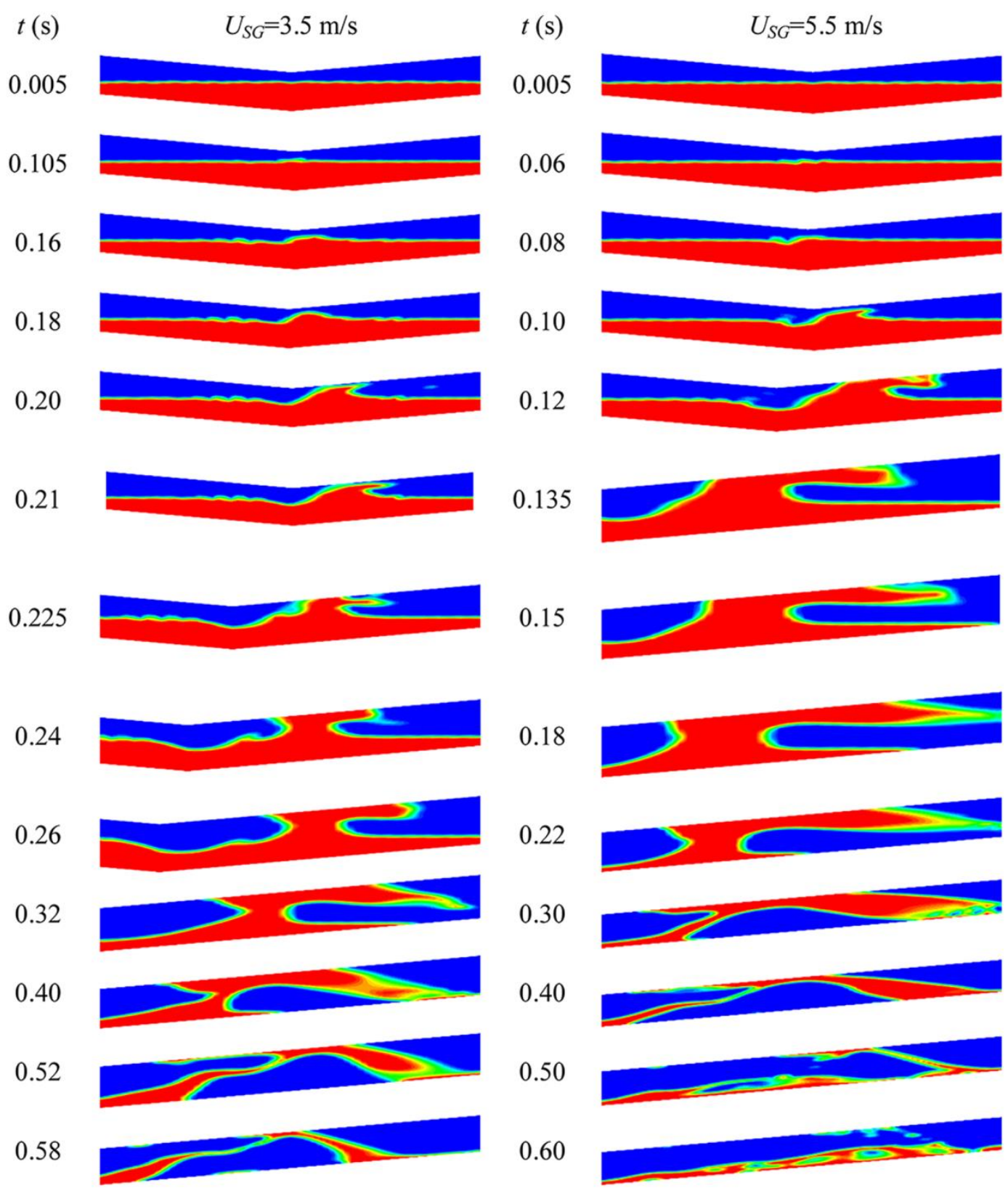

Figure 15 Gas-liquid two-phase distribution in different gas superficial velocity 


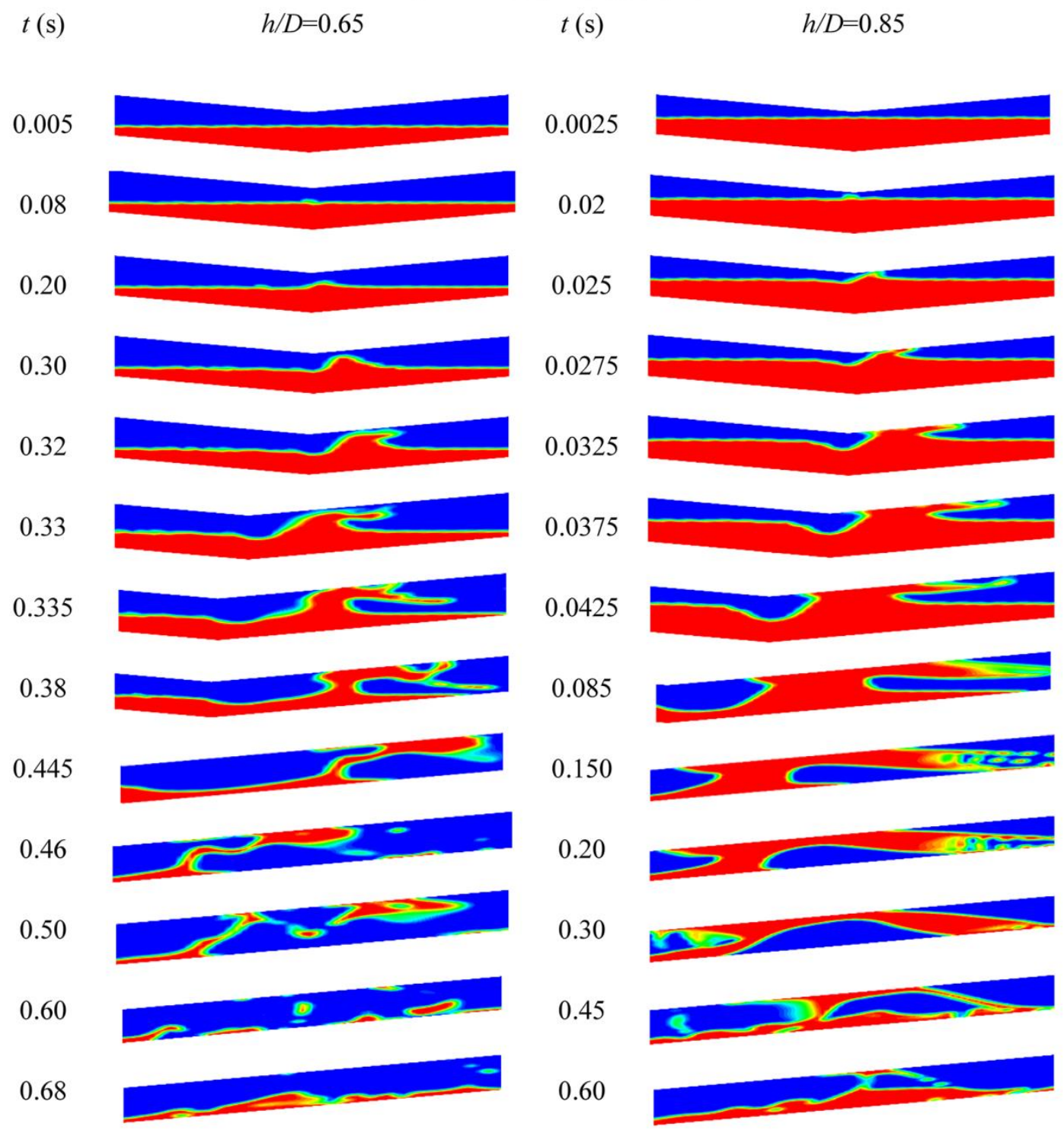

Figure 16 Gas-liquid two-phase distribution in different liquid holdup 